\title{
The Construction of the E-commerce Platform System in Collaboration with National Supply Chain
}

\author{
Jianliang Yang *, Hanping Hou, Lu Han, Mingli Yu, Bowen Qin,Tiantian Zhang, Lu Huang \\ School of Economics and Management \\ Beijing Jiaotong University \\ Beijing, China \\ yangjianliang6265@126.com
}

\begin{abstract}
With the rapid development of e-commerce, the participants of the supply chain collaboration turn into all of the node enterprises involved in. Based on the analysis of the problems existing in the supply chain collaboration, the demands and the collaboration objects, and under the guidance of the ability to adapt to the unpredictable customer needs, this paper takes the rapid reconstruction of the dynamic alliance and combines with the internet technologies to design the framework of the e-commerce platform system in collaboration with supply chain, to develop the standard structure of the platform and analyze the functions of the application system of the platform, so as to provide reference for the development of the e-commerce in collaboration with the supply chain.
\end{abstract}

Keywords-supply chain collaboration; e-commerce platform; standard structure; management of the blacklist and the whitelist

\section{INTRODUCTION}

The application of information technology promotes the development and the efficiency of supply chain management greatly. In the environment of globalized economy, crossborder e-commerce and information platform technology, collaboration among enterprises become more and more important. Based on information sharing, all the enterprises in supply chain are developing themselves, to meet the requirement of customs and enhance their service ability collaboratively with their special strength[1].

\section{OVERVIEW OF SUPPLY CHAIN COLLABORATION}

A. Definition and connotation of supply chain collaboration

Supply chain collaboration[2] means that two or more enterprises build a networked combo by protocol or organizing combination in order to achieve strategic targets. In supply chain collaboration, enterprises cooperate, support, and coordinate with each other instead of competition each other. Compared with traditional supply chain management, supply chain collaboration do not view enterprises isolated but form every enterprises into a well allocated, mutual trusted, information communicable and knowledge shared whole[3]. The collaboration of supply chain can not only enhance enterprises' core competitiveness, but also help enterprises recognize market, optimize inventory and achieve real all-win.

\section{B. Status quo of supply chain collaboration}

Modern competition is not carried out among enterprises,

This research was financially supported by the National Science and Technology Support Program (Program Number: 71132008) "Logistics resources integration and scheduling optimization research" project, and by Beijing Jiaotong University (Program Number: KBL13005530) "Development and application of integrated logistics index CMFI" project. but among supply chains. The market of supply chain in China is prospective, and plays an important role in modern service industry. Chinese enterprises keep making significant efforts in improving information level in order to realize supply chain collaboration.

However, collaboration among node enterprises is carried out mainly in the form of B2B[4]. Informatization of enterprises only takes the needs of them into account and fails to consider information exchange from and to other enterprises. Therefore, when some enterprises need to conduct business with other enterprises, they have to deal with and modify relative information into mutual acknowledged form, which means information is only exchanged between two enterprises[5](the B2B mode).

Supply chain with long chain, multiple nodes, crossindustry and cross-region has become the basic characteristics of modern supply chain. In B2B mode, a node which is located in different supply chain needs to invest a great deal of money in building information conversion interface. This impedes the built of supply chain collaboration by high cost, multiple information analyzing process. In a word, the current ecommerce mode no longer meets the need of modern supply chain collaboration.

\section{Problems in supply chain collaboration}

1) Pushing small and medium-sized enterprises into the supply chain collaboration network is difficult

Along with the global economic integration progress, big companies learn to build supply chain collaboration easier because they have more opportunities to communicate with international firms, for example the collaboration between China Oil \& Foodstuffs Corporation and Wal-Mart or Carrefour. On the contrary, it is difficult for small and mediumsized enterprises to participate in supply chain collaboration system because of the low informatization level, business ability and business consciousness.

2) Collaboration among enterprises is weak

Because enterprises in supply chain are different interest entities, and interest confliction among these enterprises exists which tends to result in agonistic behavior[6]. Besides, credit system and management mechanism is unsound. Wrong conduct of a few enterprises leads to the distrust among other enterprises, increasing the difficulty and cost of building collaboration. 
3) Development of information technology and network technology makes the supply chain collaboration more uncertain

In the complicated network environment, supply chain collaboration in B2B mode will influent the daily business activity by the difficulty of finding trusty supplier when the collaboration encounters accidents such as sudden stop of goods supply.

\section{4) Bad environment conditions and insufficient} infrastructure

Environment conditions and infrastructure in our country is far from enough to conduct a seamless collaboration of supply chain as developed countries do. Robert Easton said that in comparison with other developed countries, China has been suffered the problems of poor infrastructure, chaotic distribution system, heavy local protectionism, low 3PL ability and so on. All these factors matter a lot when China's building scaled and market-oriented supply chain collaboration.

\section{5) Inadequacy service of supply chain collaboration}

Manufacturers, dealers and government are all the main parts of supply chain collaboration market[7]. However, there is no public and effective e-commerce service mode to support the collaboration of all the main parts, leading to some problems those consumers are not able to search products information and built a round-acknowledge of the quality and safety of product.

\section{ANALYSIS OF DEMANDS AND COLLABORATION OBJECTS}

\section{A. Analysis of demands}

1) A high speed developed economy demands the supply chain collaboration

In face of all the above problems, China should seize the opportunity in changing of international information mode, research on and build collaboration service system that is suitable to our own country, and develop information-centered basic service system of supply chain collaboration to set a public benchmark for information exchange, to serve all parts in supply chain and to create condition for the enhancement of enterprises' comprehensive competitive ability.

2) Fast-moving consumer goods industry demands the supply chain collaboration

Fast-moving consumer goods industry supplies daily goods and is an important part of national economy. Basic characteristics of commodity circulation include short circulation period, low value of single good, high purchase frequency and long supply chain. The supply chain of fast moving consumer goods industry contains raw material suppliers, manufacturers, franchisers, dealers and consumers[8].

\section{B. Analysis of collaboration objects}

All participants in supply chain need information transfer to complete supply chain collaboration. Because of the different position of different participants, needs of participants differ from each other. Participants in supply chain include government sectors, Manufacture Company, Sale Company, and consumers. Structure of collaboration objects is as follows.

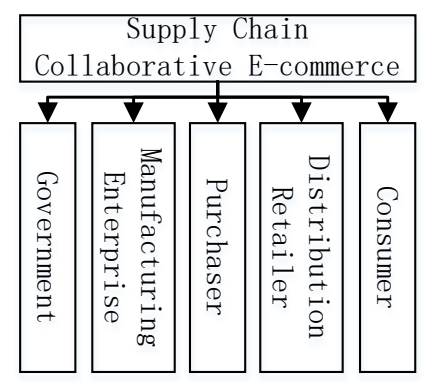

Fig. 1.Collaborative Objects

As analysis above, all the participants on the supply chain collaboration platform can be divided into three levels: government level, enterprises level and consumer level. The platform services these participants and relies on them to run, the most important of which are government level and enterprises level.

Government is both the user and the supplier of information. Government gains information of products, makes statistics, and offers relevant information to the platform. From the prospective of government, classify of participants of platform is as follows.

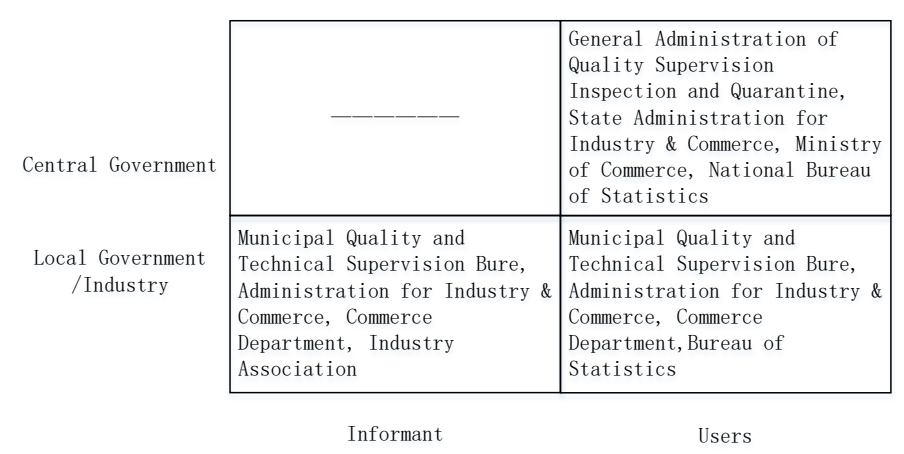

Fig. 2. The Classification Chart of Government Participants

Most of the information on the platform derives from the operation activity of enterprises, which is the most important participant on the platform. Information derived from enterprises can be divided as follows based on the business nature and operation of enterprises.

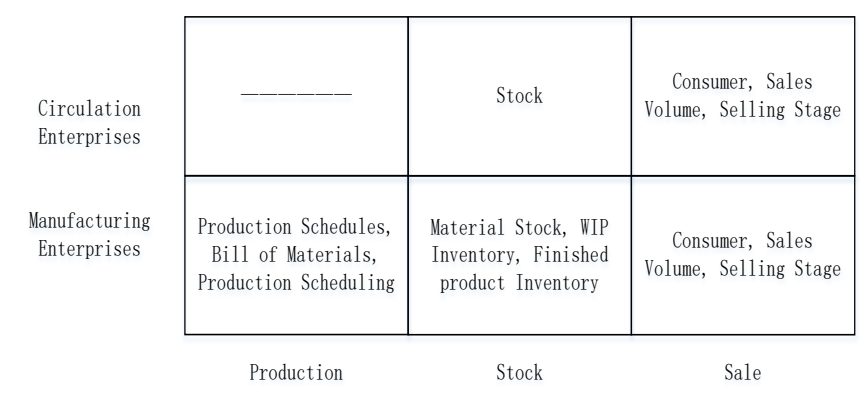

Fig. 3.The Classification Chart of Enterprise Participation 
IV. BuILD OF NATIONAL E-COMMER PlatForm OF SUPPLY CHAIN COLLABORATION

A. Basic structure of national e-commerce platform of supply chain collaboration

The structure of national e-commerce platform of supply chain collaboration is designed on the base of e-commerce application, supply chain management characteristics, and the implement method of e-commerce and supply chain collaboration, and is designed by the way of planning, coordinating and controlling of logistics information of supply chain participants. The platform contains two levels: central platform and regional/ industry platform. Structure of platform is as follows.

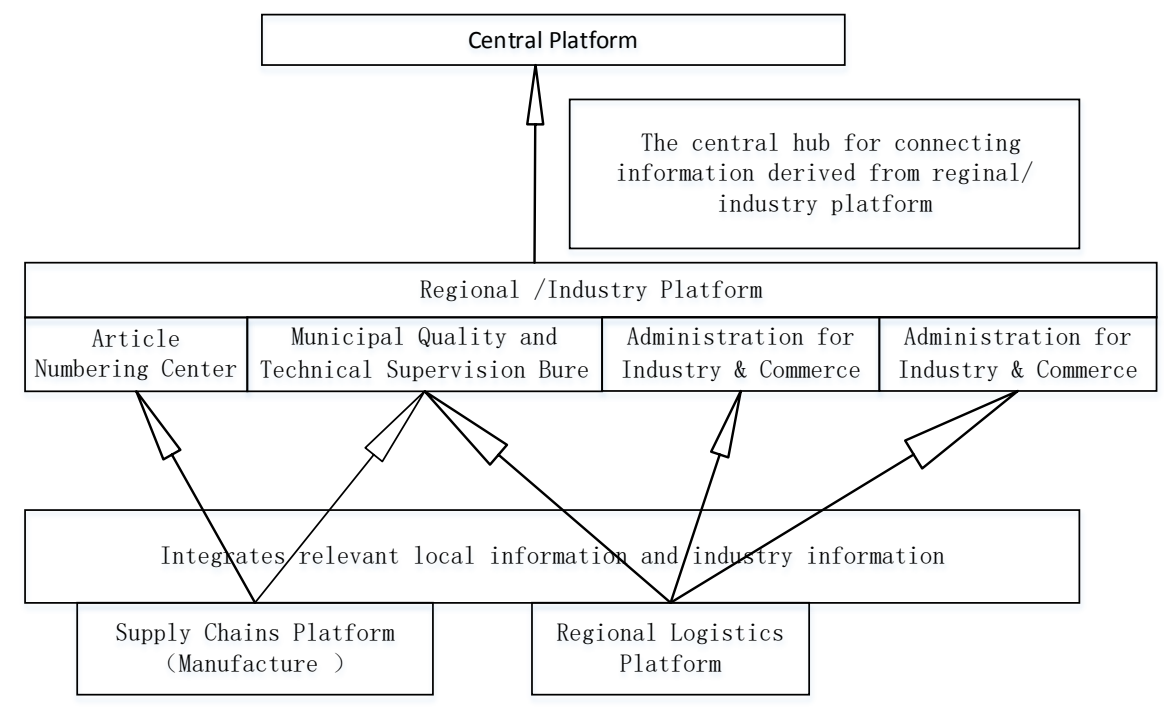

Fig. 4.The Basic Framework of National Supply Chain Collaborative E-commerce Platform

\section{1) Central platform}

Central platform is built, serviced and operated by the third part administrator assigned by State Quality Inspection Administration and is the information center of e-commerce supply chain collaboration. It is the central hub for connecting information derived from regional/ industry platform. It offers services such as address registration, address management, data backup of regional/ industry platform, and examination, decision and storage of information.

\section{2) Regional/ industry platform}

Central platform is built, serviced and operated by the third part administrator assigned by quality control system and is in charge of management and examination of regional/ industry ecommerce supply chain collaboration. It integrates relevant local information and industry information, connects with central platform, and then forms an information resource online system of communicating and sharing.

\section{B. Logical structure of national e-commerce platform of supply chain collaboration}

The whole technical structure of national e-commerce platform of supply chain collaboration contains 4 parts: application support plat form, data service platform, comprehensive display platform and operation and supervision platform. The design of technical structure needs to take many factors into account such as data quantity of connected central platform and regional/ industry platform and technical indicators of data transmission.

Structure of national e-commerce platform of supply chain collaboration follows SOA mode (Service-Oriented Architecture). Under this mode, all the interactive functions are set as independent service, which has clear defined calling interface, and can be formed into a business flow as a defined sequence. Build of the information system which is based on EAI/EIP/ nation basic platform is divided into 4 layers: data layer, application layer, service layer, access layer, and user interface layer. Logical structure of platform is as follows. 


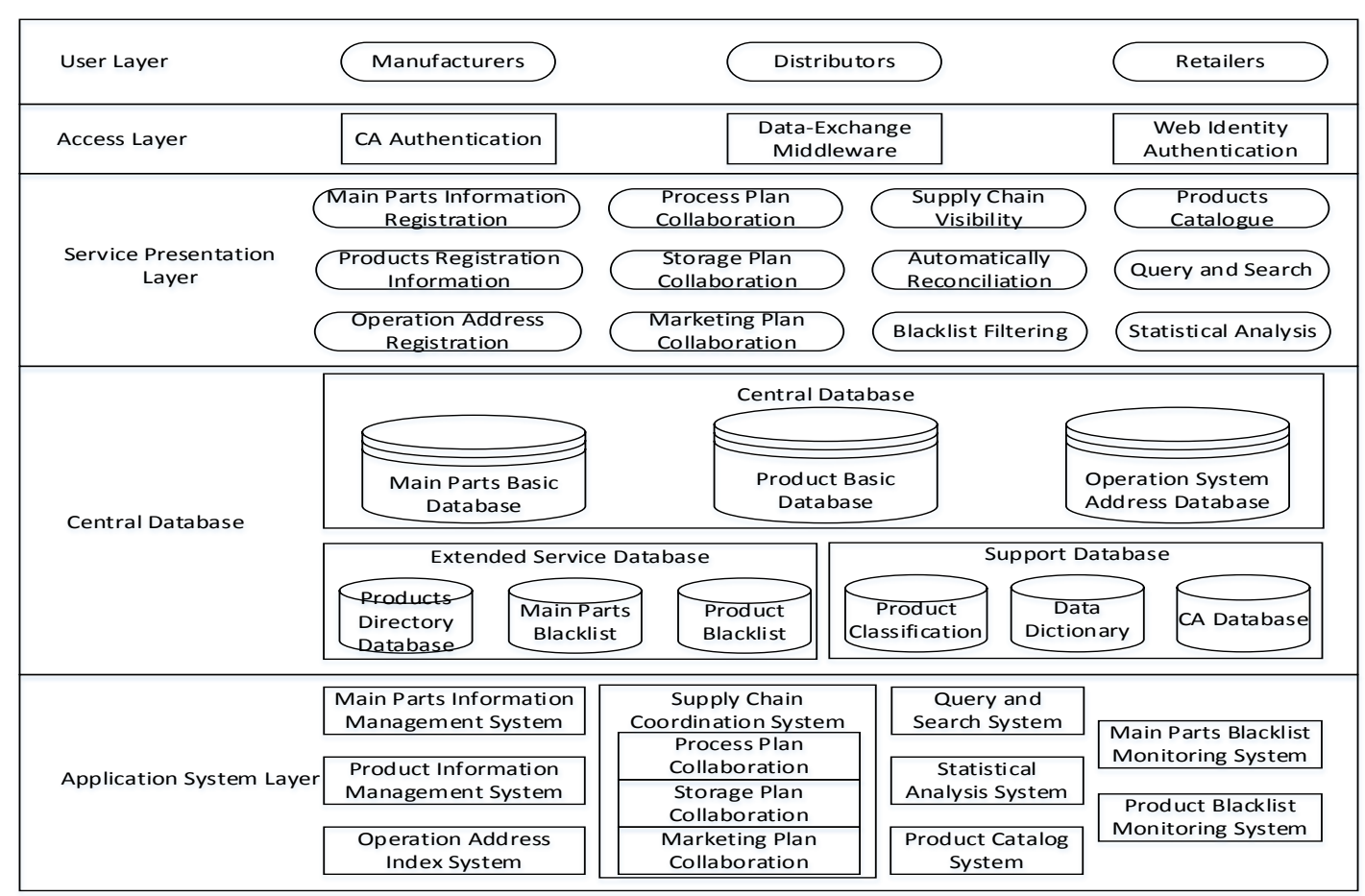

Fig. 5.Platform logical structure diagram

\section{APPLICATION STRUCTURE AND FUNCTION INTRODUCTION OF PLATFORM}

Based on six sub-systems, service system for basic information of supply chain collaboration offers basic information for collaboration business of regional/ industry platform and enterprises platform. It builds a channel for sharing and exchanging information, avoiding the case in which many channels are needed to exchange information under the "point to point"(B2B) mode. Structure of the platform is as follows.

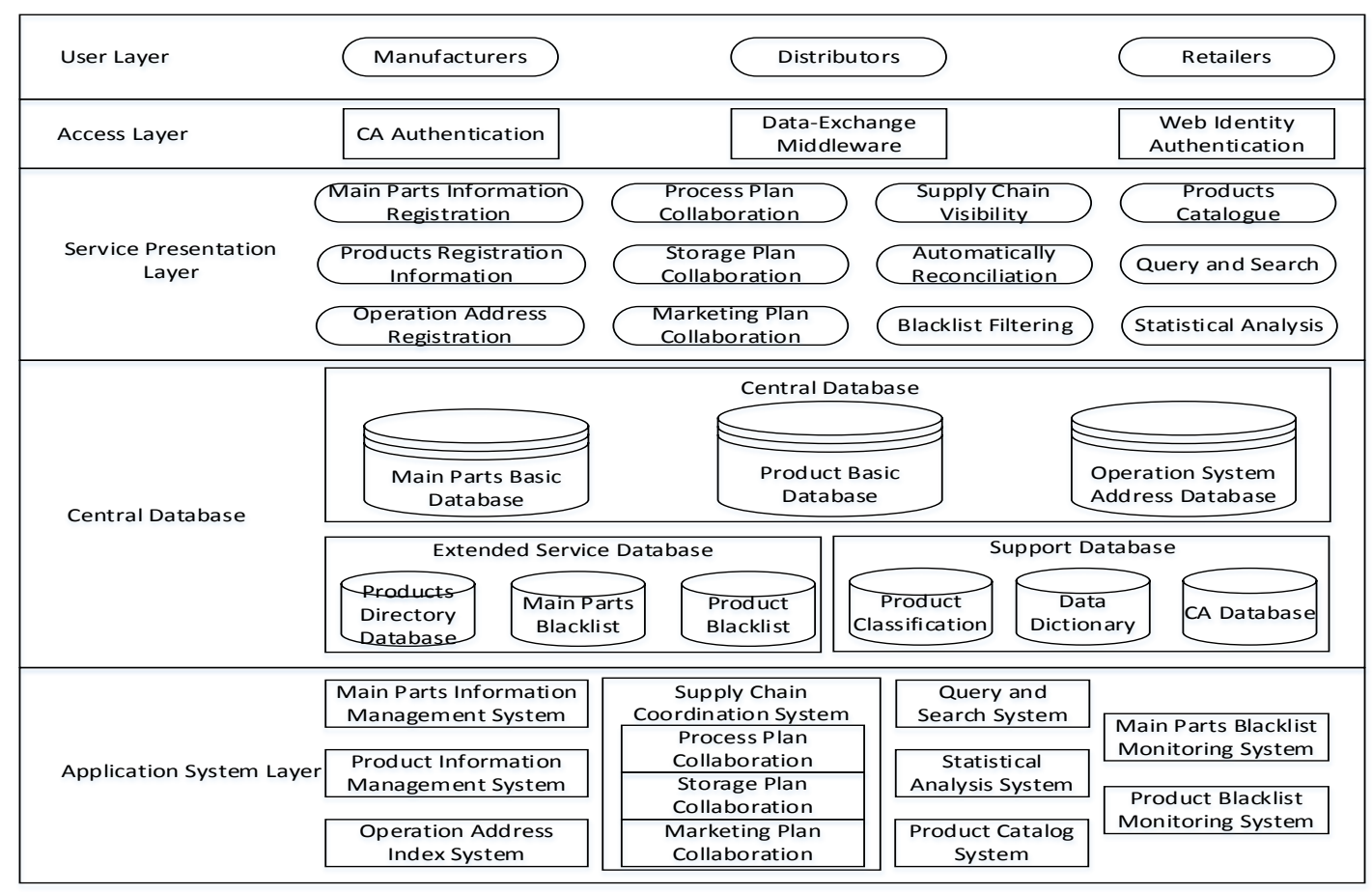

Fig. 6.Platform structure 


\section{A. Information management system of main parts in supply chain}

Basic enterprises information mainly refers to static information which is created when the company registered itself as a member of supply chain and is stored in the national enterprises database. It contains 4 function modules: enterprises main part information registration, enterprises main part information search, enterprises main part information maintenance, and enterprises main part information derivation and order.

\section{B. Basic information management system of products}

Basic information management system of products normalize and manage product information, and then form a basic information database of basic information platform of supply chain collaboration. It offers information support for other system on the platform and contains operation content such as application, registration, and search, maintain, upload and download of basic product information.

\section{Statistical and analyzing system of supply chain business}

Statistical and analyzing system of supply chain business help government access enterprises information and products information, acknowledge enterprises quantitative, product catalog and sale condition and other information. Building the sorting system and search system makes products information is easy to be found. This system contains subsystems: statistical and analyzing system, sorting system of products, and searching system of products.

\section{Management system of black list and whitelist}

Management system of black list and whitelist compares enterprises and production inspection information picked from institute of quality assurance and relative department and product data picked from the central platform. If both of this information is about sub-quality products, the company that these products are belongs to will be list on the blacklist. Central platform will update and release blacklist and white list in order to warn relative enterprises. This management system mainly contains 4 functions: releasing and searching blacklist, caution of black system, releasing and searching whitelist, and blacklist and whitelist information derivation and order.

\section{E. Service system of product catalog}

Service system of product catalog is a display platform for product where enterprises can type in products, make a product list, and release this information. Users can search or order products through this system and get comprehensive products information. This system contains two main functions: management of products list and release of products list.

\section{F. Management and indexing system of operation address}

Management and indexing system of operation address mainly deal with static information derived from business of manufacturing, storing, and sales and offers system service for system members. Registration information of enterprises address is stored in address management database of central platform business. It mainly contains 4 functions: business address registration, business address maintenance, business address index, and business address research.

\section{G. Collaboration system of supply chain process plan}

Process plan collaboration of core enterprises is embodied in the collaboration when purchasing products and choosing suppliers, in the schedule management collaboration, and in the return management collaboration. It mainly contains 3 functions: process management, order status search, return management.

\section{H. Collaboration system of supply chain storage plan}

Manufacturers and distributers can search storage information from each other by putting in product number and other information.

\section{Collaboration system of supply chain marketing plan}

Based on product marketing plan, manufacturers can release product information to regional platform in the form of products catalog. At the same time, manufacturers can search for suitable distributers in enterprises database of central platform. Both manufacturers and distributers can find each other, reach a cooperation agreement, make marketing plan and conduct business in collaboration system of supply chain marketing plan.

\section{CONCLUSIONS}

This article focuses on e-commerce supply chain collaboration and makes innovations on exploitation and application of e-commerce by research. Developing specification management platform for supply chain collaboration, this article tackles problems of non-standard technology, poor coordination, and low service effectiveness and so on, to form a strong system foundation for e-commerce. This system could help to enhance the collaboration among enterprises, promote core competence of the corporation of China's industry, and increase the innovation in servicing mode and technology integration.

\section{REFERENCES}

[1] RiddallS C E,Bennett S. Produc “on-Inventory system Controner Design and Supply Chain Dynamic[J]. International JournaI of Systems Science,2002(3):18l 195.

[2] Gopal Kumar,Rabindra Nath Banerjee.Supply chain collaboration index:an instrument to measure the depth of collaboration[J]. Benchmarking:An International Journal. 2014,21(2):184 204.

[3] Florian Kache,Stefan Seuring.collaboration and integration to risk and performance in supply chains via a review of literature reviews[J]. Supply Chain Management:An International Journal. 2014,19(5):664 682.

[4] Jengchung Victor Chen,Yawen Chen,Erik Paolo S. Capistrano.Process quality and collaboration quality on B2B e - commerce[J]. Industrial Management \& Data Systems. 2013,113(6):908 926.

[5] Ismail Sila,Dawn Dobni,Patterns of B2B e - commerce usage in SMEs[J]. Industrial Management \& Data Systems. 2012,112(8):1255 1271.

[6] Ben Tal A,Golang B,NemiroVsk A.Retailer-Supplier Flexible Commitments Contracts:A Robust Optimization Approach[J]. Manufacturing and SerVice Operation Management, 2005(3):248 271.

[7] S.Alex Yang,John R.Birge,Rodney P.Parker.The Supply Chain Effects of Bankruptcy[J]. Management Science, 2015(3),2320 2338.

[8] Adriana Rossiter Hofer,Christian Hofer,Matthew A.Waller.What gets suppliers to play and who gets the pay? On the antecedents and outcomes of collaboration in retailer-supplier dyads[J]. The International Journal of Logistics Management, 2014,25(2):226〜244. 